\title{
Ocular Phenotypic Features of Adult-Onset Primary Open Angle Glaucoma in A Tertiary Hospital in Southern Nigeria
}

\section{Onua AA and Ordinioha B*}

School of Public Health, University of Port Harcourt, Nigeria

*Corresponding Author: B Ordinioha, School of Public Health, University of Port Harcourt, Nigeria.

DOI: $10.31080 /$ ASOP.2022.05.0466
Received: January 21, 2022

Published: February 10, 2022

(C) All rights are reserved by Onua AA and

Ordinioha B.

\begin{abstract}
Background/Objective: This was a prospective study of patients diagnosed with adult-onset Primary Open Angle Glaucoma (POAG) at the Glaucoma Clinic at the University of Port Harcourt Teaching Hospital, Nigeria. The objective of the study was to determine the ocular phenotypic features of patients with adult-onset glaucoma.

Materials and Methods: Clinical assessment of patients combined with findings from clinical records and interviewer administered semi-structured questionnaire were used to obtain data from the respondents between January and December 2021. Results: One thousand two hundred $(n=1200)$ adult POAG patients aged $\geq 40$ years were recruited. The mean age of the subjects was $56.5 \pm$ SD 22.3 years. Male-female ratio was 2.9:1. The mean central corneal thickness (CCT) was $532 \pm$ SD $8.6 \mu$ m and average intraocular pressure (IOP) was $31.3 \pm$ SD $11.2 \mathrm{mmHg}$. Nine hundred and three subjects ( $\mathrm{n}=903 ; 75.3 \%$ ) had high intraocular pressure $(\geq 22 \mathrm{mmHg}$ ). Over $25 \%$ had poor ocular perfusion pressure $(\leq 40 \mathrm{mmHg})$. Six hundred and forty-seven $(\mathrm{n}=647 ; 53.9 \%)$ had positive family history of glaucoma (first degree relatives) while 234 (19.5\%) had positive family history of glaucoma (second degree relatives). Eight hundred and twenty $(n=820 ; 68.3 \%)$ subjects had cupping of the optic disc (VCDR $\geq 0.7)$. All the study participants had II to IV degree of open drainage angle on gonioscopy.

Conclusion: Thin CCT, high IOP, large VCDR poor OPP, and open drainage angle are noticeable ocular phenotypic features of adultonset primary open angle glaucoma. Early detection through community-based case detection using these parameters could help in reducing the scourge from POAG.
\end{abstract}

Keywords: Adult-Onset Primary Open Angle Glaucoma; Phenotypic Features; Southern Nigeria

\section{Introduction}

Glaucoma is the second commonest cause of blindness after cataract and a leading cause of irreversible blindness; accounting for $0.3 \%$ of blindness in the world $[1,2]$. Glaucoma is also the leading cause of irreversible blindness in Nigeria - being responsible for 15 - 20\% of blindness in Nigeria [3]. Primary open angle glaucoma disproportionately affects individuals of African ancestry and is the most common cause of permanent blindness in Africa [4] and the Africa region has the highest incidence and prevalence of glaucoma [5].
Adult-onset Primary open-angle glaucoma is the most prevalent variant in Nigeria; and the Niger Delta Region has the highest number of glaucoma patients in Nigeria - being responsible for for $20.8 \%$ of bilateral blindness [6]. POAG is usually asymptomatic until it progresses to irreversible blindness. Most patients in Africa have poor or inadequate knowledge of glaucoma, and therefore present very late for clinical evaluation and treatment. In addition, there is often reluctance in the acceptance of medical and surgical intervention among African populations [7-9]. 
Most ophthalmologists consider that blindness from POAG can be prevented if the pre-symptomatic stages are detected early and corresponding adequate treatment instituted. It has been reported that there may be 40 - 50 percent structural axonal loss before any significant functional change is detected [10]. There is therefore a need to improve on the methods of early diagnosis by being able to identify the phenotypic characteristics of adult-onset POAG to enhance preclinical screening, early diagnosis and treatment of individuals at risk.

The genetic constitution or makeup of an individual determines their hereditary potentials, physical structure, manifestations and functions (phenotype). During transcription, the information stored in a gene's DNA is transferred to messenger ribonucleic acid (mRNA) in the cell nucleus. The mRNA interacts with a ribosome, which "reads" the sequence of mRNA bases. Each sequence of three bases (codon) usually codes for one particular amino acid which is the building blocks of proteins. Many important risk factors and features of adult-onset primary open angle glaucoma (POAG) such as the central corneal thickness (CCT), intraocular pressure (IOP), trabeculum meshwork (TM), drainage angle, cup-disc-ratio of the optic disc head and retinal nerve fiber layer thickness are heritable traits and are likely determined in part by the actions of genes are controlled by a number of genes as well as environmental influences [11-14].

This study investigates the ocular phenotypic features of adultonset POAG patients attending the Glaucoma Clinic of the University of Port Harcourt Teaching Hospital in Southern Nigeria Knowledge and the identification of the ocular phenotypic features of the disease will be invaluable in the early diagnosis and treatment of the disease, leading to overall improvement in the management of POAG.

\section{Materials and Methods}

This was a prospective study of 1,200 patients attending the Glaucoma clinic, department of ophthalmology at the University of Port Harcourt Teaching Hospital, Nigeria; diagnosed with adultonset Primary Open Angle Glaucoma (POAG). The study was carried out between January and December 2021. Measurement of the distant and near visions of consenting subjects was done at a distance of 6 meters with the aid of illuminated Snellen's chart, pin hole and at $40 \mathrm{~cm}$ for near vision. Basic ocular examinations (which included evaluation of the eyelids, the globe, cornea, pupil and the lens) were done with the aid of a bright pen touch and slit lampTopview optics'slit lamp-LS-4. Fundoscopy was carried out with +78D lens. Pupillary dilatation was achieved using Mydriacyl 0.5\% after refraction and measurement of the intraocular pressure. Intraocular pressure measurement was done using Perkin's applanation tonometer (MK2-model), after instilling local anaesthetic agent (1\% tetracaine) and fluorescein dye into the conjunctival sac. IOPs was measured in both eyes three consecutive times. The measurements were done with the subjects in sitting position. The mean IOP value was adopted. CCT measurements were obtained with ultrasonic pachymetry (Tomey SP-3000, Tomey Ltd, Japan.) under topical anesthesia with tetracaine 1\%. Measurements were obtained three times from the center of the cornea and the average reading was adopted. All the measurements were carried out by the lead-author to avoid inter-observers' error.

The data obtained were entered into Microsoft Excel sheet, cleansed and later exported to IBM Statistical Package for Social Sciences (SPSS) version 25 software (SPSS) Inc; Chicago, IL, USA for statistical analysis. Relevant data were presented in tables and charts. Statistical significance was performed using Chi square and statistical significance was set at $\mathrm{p} \leq 0.05$.

\section{Results}

The age-gender distribution of the study population is presented in table 1. One thousand two hundred adult-onset POAG patients ( $\geq 40$ years) were seen during the period of this study representing $60.4 \%$ of the total number of glaucoma patients seen during the same period. The mean age of the study population was $56.5 \pm$ SD 22.3 years. Age range was 40 to 88 years and male-female ratio was 2.9:1. The modal age group was 60 - 69 years. The difference in the ages of the participants was statistically significant $(p$ $=0.000$ ) (Table 1$)$.

Table 2 depicts the ocular characteristics (CCT, VCDR) and family history of glaucoma among the subjects recruited in the study. The mean central corneal thickness (CCT) was $532.5 \pm 8.6 \mu \mathrm{m}$. Eight hundred and twenty-eight $(69.0 \%)$ of the subjects had thin central corneal thickness $(<500 \mu \mathrm{m}) ; 238$ (19.9\%) had average central corneal thickness (501 - $570 \mu \mathrm{m})$ while 134 (11.1\%) had thick central corneal thickness $(>570 \mu \mathrm{m})$. This difference in the central corneal thickness among the study population was statistically significant $(\mathrm{p}=0.000)$. 


\begin{tabular}{|l|c|c|c|c|c|}
\hline & No Male (\%) & No Female (\%) & Total (\%) & Chi Square Value & P-Value \\
\hline Age Group & & & & 32.333 & 0.000 \\
\hline $40-49$ & $85(7.1)$ & $35(2.9)$ & $120(10.0)$ & & \\
\hline $50-59$ & $314(26.1)$ & $96(8.0)$ & $410(34.1)$ & & \\
\hline $60-69$ & $440(36.7)$ & $120(10.0)$ & $560(46.7)$ & & \\
\hline $70-79$ & $32(2.7)$ & $33(2.8)$ & $65(5.5)$ & & \\
\hline 80 and Above & $28(2.3)$ & $17(1.4)$ & $45(3.7)$ & & \\
\hline TOTAL & $899(74.9)$ & $301(25.1)$ & $1200(100)$ & & \\
\hline
\end{tabular}

Table 1: Age-gender distribution of the study population.

\begin{tabular}{|l|c|c|c|}
\hline Variable & $\begin{array}{c}\text { Distribution in Adult } \\
\text { Onset POAG Cases }\end{array}$ & Chi Square & P-Value \\
\hline Central Corneal Thickness (CCT) & (N) (\%) & 324.225 & 0.000 \\
Thin Cornea $(\leq 500 \mu)$ & $238(19.9)$ & \\
Average Cornea $(501-570 \mu)$ & $134(11.1)$ & \\
Thick Cornea $(>570 \mu)$ & $1200(100)$ & \\
TOTAL & $820(68.3 \%)$ & \\
\hline Vertical Cup Disc Ratio (VCDR) & $360(30.0)$ & \\
$\geq 0.7$ & $20(1.7)$ & \\
$0.5-0.65$ & $1200(100)$ & \\
$\leq 0.45$ & $234(19.5)$ & \\
TOTAL & $319(26.6)$ & \\
\hline Positive Family History of Glaucoma & $1200(100)$ & \\
First Degree Relative & & \\
Second Degree Relative & & \\
Unaware & & \\
TOTAL & & \\
\hline
\end{tabular}

Table 2: Ocular characteristics of subjects recruited for the study.

Eight hundred and twenty subjects (68.3\%) had abnormally large cupping of the optic disc (VCDR $\geq 0.7$ ) while three hundred and sixty (30\%) had suspicious cupping (VCDR 0.5 - 0.65) and normal VCDR were exhibited by 20 (1.7) respondents. The difference in the VCDR of the respondents in this study was statistically significant $(\mathrm{p}=0.000)$.
Six hundred and forty-seven (53.9\%) had positive family history of glaucoma (first degree relatives) while 234 (19.5\%) had positive family history of glaucoma (second degree relatives).

The mean intraocular pressure (IOP) of the patients at presentation was $31.3 \pm$ SD $11.2 \mathrm{mmHg}$. Nine hundred and three subjects $(75.3 \%)$ had high intraocular pressure $(\geq 22 \mathrm{mmHg})$. 


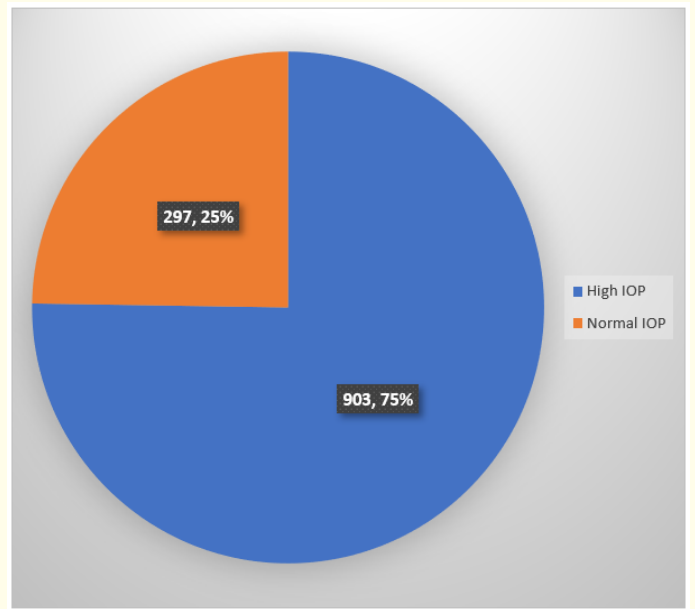

Figure 1: Intraocular pressure of the study population at presentation.

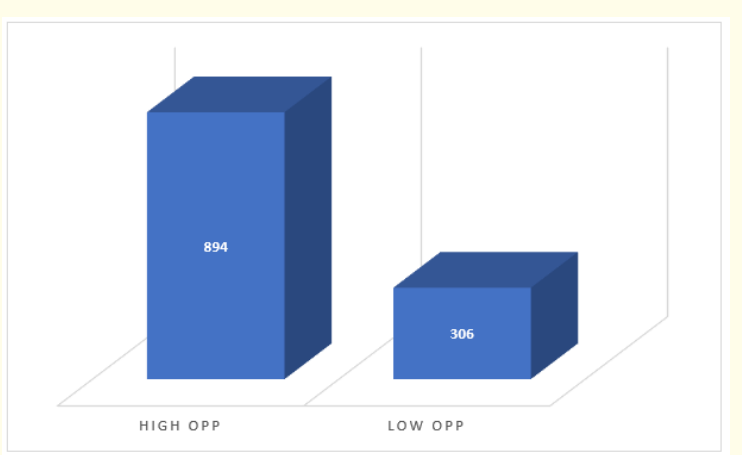

Figure 2: Ocular Perfusion pressure (OPP) of the study population at presentation

Slightly over $25 \%$ (306) subjects had poor ocular perfusion pressure $(\leq 40 \mathrm{mmHg})$.

\section{Discussion}

A total of 1,200 consenting subjects aged 40 years and above were recruited into this study representing $60.4 \%$ of the total number of glaucoma patients seen during the same period. The agegender distribution of the study population is presented in table 1. The mean age of the study population was $56.5 \pm$ SD 22.3 years. Age range was 40 to 88 years and male-female ratio was 2.9:1. The modal age group was 60 - 69 years. The difference in the ages of the participants among the various age groups was statistically significant $(\mathrm{p}=0.000)$ (Table 1$)$.

This study corroborates with the work of Awoyesuku., et al where there was also male preponderance in a retrospective study of 98 glaucoma patients with mean age of $49.7 \pm 14.06$ years in a Southern Nigerian tertiary hospital [15]. Many researchers have also, identified age to be a major risk factor for POAG [16-18].

The central corneal thickness (CCT) is a phenotypic feature of POAG associated with a strong heritability trait ${ }^{11,19}$. Studies suggest that subjects of African descent African have thinner corneas than Caucasians and harbor a higher incidence and prevalence of glaucoma [20-23]. CCT affects the accuracy of intraocular pressure (IOP) measurement by applanation tonometry,thicker cornea requires greater force to flatten and, conversely, a thinner cornea is more easily flattened, thus a thinner cornea may give rise to a falsely lower IOP than the actual value [24]. In this study, the mean central corneal thickness (CCT) was $532.5 \pm 8.6 \mu \mathrm{m}$. Eight hundred and twenty-eight (69.0\%) of the subjects had thin central corneal thickness $(<500 \mu \mathrm{m}) ; 238(19.9 \%)$ had average central corneal thickness (501 - $570 \mu \mathrm{m})$ while 134 (11.1\%) had thick central corneal thickness $(>570 \mu \mathrm{m})$. This difference in the central corneal thickness among the study population was statistically significant ( $p=0.000$ ) (Table 2). Our findings corroborate with the work of Uche., et al; 2021 who found that the average central corneal thickness (CCT) among black population in Eastern Nigeria was 527.68 $\pm 36.88 \mu \mathrm{m}[24]$.

Family history of glaucoma increases the risk of an individual developing the disease. Although the exact inheritance pattern is still unknown, adult-onset POAG is a multifactorial polygenetic disease. In this study, 647 subjects (53.9\%) had positive family history of glaucoma (first degree relatives) while 234 (19.5\%) had positive family history of glaucoma (second degree relatives) (Table 2). Our observation, therefore, substantiates the findings of the Barbados family study of Open-angle Glaucoma, Glaucoma Inheritance Study in Tasmania and the Rotterdam study which found that family history of glaucoma is a risk factor for developing POAG [25].

The role of ocular perfusion pressure in the development and progression of POAG continues to generate attention among investigators. The balance between IOP and systemic blood pressure, influenced by the autoregulatory capacity of the eye, is part of what 
determines whether an individual will develop optic nerve damage. The relationship between systemic blood pressure (BP), ocular perfusion pressure (OPP) and POAG is multifaceted. Blood pressure is a component of OPP. Hence, it would be expected that higher BPs (theoretically related to a higher OPP) decreased the risk of OAG. However, an increased BP could lead to a reduced blood vessel diameter, due to vasoconstriction in the short term, and in the long-term arteriosclerosis (thickening of the vessels walls), and therefore decreased ocular blood flow, enhancing the risk of POAG [26]. Moreover, elevated peripheral vascular resistance is usually involved in the pathogenesis of systemic hypertension, contributing to localized end organ damage, where the volume of flow is deficient [27].

In this study, slightly over 25\% (306) adult-onset POAG subjects had low ocular perfusion pressure $(\leq 40 \mathrm{mmHg})$ at presentation. Our observation corroborates the findings of some other researchers [26,28-35] in which the relationship between OPP and POAG have shown that low OPP is a risk factor for the prevalence, incidence and progression of glaucoma. However, more prospective, longitudinal studies are needed to show this observation among people of Niger-Delta region of Nigeria.

The vertical cup disc ratio (VCDR) of the optic nerve head, is useful clinically, especially to guide clinicians in the diagnosis of glaucoma. Attempts have been made to find a useful VCDR cut off value to differentiate normal and glaucomatous optic disc cupping. The proportion of normal subjects with a VCDR of 0.65 or greater ranged from about $2.2 \%$ to $4 \%$ [36]. The incidence of visual field defects increases markedly with VCDRs greater than 0.7 in glaucoma. However, the ability of the VCDR to distinguish between normal and early glaucomatous optic disc has been found to be poor with a sensitivity and specificity of $64 \%$ and $57 \%$ respectively from a clinic-based study [37]. The findings in our work agrees with the postulation that glaucoma patients are associated with abnormally high VCDR. With a cut off VCDR value of $\geq 0.7$, we observed that $68.3 \%$ of adult-onset POAG population had abnormal cupping of the optic disc, 30\% had suspicious cupping (VCDR 0.5 - 0.65) and $1.7 \%$ exhibited normal VCDR $\geq 0.45$. This difference was statistically significant $(\mathrm{p}=0.000)$ (Table 3 ).

\section{Conclusion}

Ocular phenotypic features of adult-onset primary open angle glaucoma (POAG) among patients in Southern Nigeria are similar to those reported in other countries of the world-high IOP, high VCDR, poor OPP, and open drainage angle. Early detection through community-based case detection using these parameters could help in reducing the scourge arising from POAG among our population.

\section{Financial Support and Sponsorship}

This work had financial support from Tertiary Education Trust Fund (TET Fund) Institution- Based Research Grant of the University of Port Harcourt, Nigeria.

\section{Conflicts of Interest}

There are no conflicts of interest.

\section{Bibliography}

1. Bourne RRA., et al. "Magnitude, temporal trends, and projections of the global prevalence of blindness and distance and near vision impairment: a systematic review and meta-analysis". The Lancet Global Health 5.9 (2017): e888-897.

2. World Health Organization. Magnitude and cause of visual impairment. WHO Fact Sheet No. 282. Geneva: WHO (2019).

3. Abdull MM., et al. "Causes of blindness and visual impairment in Nigeria: The Nigerian National Blindness and Visual Impairment Survey". Investigative Ophthalmology and Visual Science 50.9 (2009): 4114-4120.

4. Klein BE., et al. "Heritability of risk factors for primary openangle glaucoma: The Beaver Dam Eye Study". Investigative Ophthalmology and Visual Science 45 (2004): 59-62.

5. Quigley HA and Broman AT. "The number of people with glaucoma worldwide in 2010 and 2020". British Journal of Ophthalmology 90 (2006): 262-267.

6. Pedro-Egbe CN., et al. "Blindness and Visual Impairment in the Niger-Delta: A study of Ahoada-East Local Government Area of Rivers State, Nigeria". BMC Public Health 1.1 (2006): 56-61.

7. Rotchford A. "What is practical in glaucoma management?" Eye 19.10 (2005): 1125-1132.

8. Bowman RJ and Hay A. "Combined cataract and trabeculectomy surgery for advanced glaucoma in East Africa: visual and intra-ocular pressure outcomes". Eye 24 (2010): 573-577.

9. Adekoya BJ., et al. "Glaucoma in Southwest Nigeria: Clinical presentation, family history and perceptions". International Ophthalmology 34 (2014): 1027-1036. 
10. Quingley HA., et al. "Optic nerve damage in human glaucoma III; quantitative correlation of nerve fibre loss and visual field defect in glaucoma, ischemic neuropathy, papilledema and toxic neuropathy". Acta Ophthalmologica 100 (1982): 135146.

11. Toh TY., et al. "Central corneal thickness is highly heritable: the twin eye studies". Investigative ophthalmology and Visual Science 46.10 (2005): 3718-3722.

12. Chang TC., et al. "Determinants and heritability of intraocular pressure and cup-to-disc ratio in a defined older population". Ophthalmology 112 (2005): 1186-1191.

13. Klein BE., et al. "Heritability of risk factors for primary openangle glaucoma: The Beaver Dam Eye Study". Investigative Ophthalmology and Visual Science 45 (2004): 59-62.

14. Van Koolwijk LM., et al. "Genetic contributions to glaucoma: heritability of intraocular pressure, retinal nerve fiber layer thickness, and optic disc morphology". Investigative Ophthalmology and Visual Science 48 (2007): 3669-3676.

15. Awoyesuku EA and Pedro-Egbe CN. "Clinical forms of glaucoma in a tertiary hospital in Nigeria". Port Harcourt Medical Journal 6 (2012): 333-338.

16. Kreft D., et al. "Prevalence, incidence, and risk factors of primary open-angle glaucoma - a cohort study based on longitudinal data from a German public health insurance". BMC Public Health 19 (2019): 2295-2302.

17. Friedman DS., et al. "The prevalence of open-angle Glaucoma among blacks and whites 73 years and older: the Salisbury eye evaluation Glaucoma study". Archives of Ophthalmology 124 (2006): 1625-1630.

18. Awoyesuku EA., et al. "The Port Harcourt Hospital Glaucoma Study". British Journal of Medicine and Medical Research 21.9 (2017): 1-6.

19. Landers JA., et al. "Heritability of central corneal thickness in nuclear families". Investigative Ophthalmology and Visual Science 50.9 (2009): 4087-4090.

20. Aghaian E., et al. "Central corneal thickness of Caucasians, Chinese, Hispanics, Filipinos, African Americans, and Japanese in a glaucoma clinic". Ophthalmology 111.12 (2004): 2211-2219.

21. Wang SY., et al. "The impact of central corneal thickness on the risk for glaucoma in a large multiethnic population". Journal of Glaucoma 23.9 (2014): 606-612.
22. Chua J., et al. "Ethnic differences of intraocular pressure and central corneal thickness: the Singapore Epidemiology of Eye Diseases study". Ophthalmology 121.10 (2014): 2013-2022.

23. Pan CW., et al. "Ethnic Variations in Central Corneal Thickness in a Rural Population in China: The Yunnan Minority Eye Studies". PloS one 10.8 (2015): e0135913.

24. Uche NJ., et al. "Central Corneal Thickness in an Adult NonGlaucomatous Ethnic Population in Nigeria". Research Square (2021).

25. Wu J., et al. "Disease severity of familial glaucoma compared with sporadic glaucoma". Archives of Ophthalmology 124 (2006): 950-954.

26. Ramdas WD., et al. "Ocular perfusion pressure and the incidence of glaucoma: real effect of artifact? The Rotterdam Study". Investigative Ophthalmology and Visual Science 52 (2011): 6875-6881.

27. Oparil S., et al. "Pathogenesis of hypertension". Annals of Internal Medicine 139 (2003): 761-776.

28. Omoti AE., et al. "Vascular risk factors for open angle glaucoma in African eyes". Middle East African Journal of Ophthalmology 16 (2009): 146-150.

29. Xu L., et al. "Ocular perfusion pressure and glaucoma: the Beijing Eye Study”. Eye 23 (2009): 734-737.

30. Memarzadeh F., et al. "Blood pressure, perfusion pressure, and open-angle glaucoma: the Los Angeles Latino Eye Study". Investigative Ophthalmology and Visual Science 51 (2010): 28722877.

31. Zheng Y., et al. "Distribution of ocular perfusion pressure and its relationship with open-angle glaucoma: the Singapore Malaysia eye study". Investigative Ophthalmology and Visual Science 51 (2010): 3399-3404.

32. Quigley HA., et al. "The prevalence of glaucoma in a population-based study of Hyspanic subjects: Proyecto VER". Archives of Ophthalmology 119 (2001): 1819-1826.

33. Mitchell P., et al. "Open-angle glaucoma and systemic hypertension: the blue mountains eye study". Journal of Glaucoma 13 (2004): 319-326.

34. Leske MC., et al. "Predictors of long-term progression in the early manifest glaucoma trial". Ophthalmology 114 (2007): 1965-1972. 
35. Orzalesi N., et al. "Vascular risk factors in glaucoma: the results of a national survey". Graefe's Archive for Clinical and Experimental Ophthalmology 245 (2007): 795-802.

36. Carpel EF and Engstrom PF. "The normal cup-disk ratio". Acta Scientific Ophthalmology 91 (1981): 588-597.

37. O'Connor DJ., et al. "Comparison of methods to detect glaucomatous optic nerve damage". Ophthalmology 100 (1993): 1498-503.

\section{Assets from publication with us}

- Prompt Acknowledgement after receiving the article

- Thorough Double blinded peer review

- Rapid Publication

- Issue of Publication Certificate

- High visibility of your Published work

Website: www.actascientific.com/

Submit Article: www.actascientific.com/submission.php

Email us: editor@actascientific.com

Contact us: +919182824667 